\title{
NOTE \\ An Acute Increase in Serum Prolactin Does Not Modify Gonadotropin Release in Female Rats
}

\author{
Shinnosuke KAWAGOE, Hideyuki TAKAHASHI \\ AND MASAHIKO HIROI \\ Department of Obstetrics and Gynecology, Yamagata University School \\ of Medicine, Zao-iida, Yamagata 990-23.
}

\begin{abstract}
Attempts were made to find out whether hyperprolactinemia has an effect on the hypothalamo-pituitary response to estrogen feedback and LHRH stimulation. Adult female rats of Wistar strain were ovariectomized and received subcutaneous injection of $20 \mu \mathrm{g}$ estradiol benzoate (EB) 3-4 weeks later (day-0). A second injection of $20 \mu \mathrm{g}$ EB, when administered at noon on day-3, induced a highly significant increase in serum LH ( $p<0.001$ vs. basal values), but not FSH, estimated at $1800 \mathrm{~h}$ on the same day. This EB-promoted LH release was not altered by pretreatment with rat PRL $(5 \mu \mathrm{g} /$ day $)$, which was administered subcutaneously daily in the morning $(1100 \mathrm{~h})$ between day-1 and day-3. No statistical difference in the serum LH concentration was found when compared with the values for the control animals pretreated with $0.9 \%$ saline alone.

Serum gonadotropins $15 \mathrm{~min}$ after LHRH administration $(100 \mathrm{ng} / 100 \mathrm{~g} \mathrm{BW})$ in 32 day-old female rats were not statistically different between the animals pretreated with $5 \mu \mathrm{g}$ PRL, which was given subcutaneously daily (at $0800 \mathrm{~h}$ ) for 3 days, and the controls pretreated with $0.9 \%$ saline. These results suggest that an acute increase in serum PRL may not exert a negative effect on the gonadotropin release induced by estrogen feedback and LHRH stimulation.
\end{abstract}

The mechanism by which excessive prolactin (PRL) leads to hypogonadism remains obscure. There is evidence to suggest that PRL by itself exerts an antigonadotropic effect on the ovary (Faglia et al., 1977). It has also been suggested that PRL has an inhibitory effect on gonadotropin secretion at the hypothalamo-pituitary level. Several investigators (Glass et al., 1975; Faglia et al., 1977 ; Aono et al., 1979) have demonstrated an impaired hypothalamic response to positive estrogen feedback in hyperprolactinemic women and have reported a restoration of the response when serum PRL levels are lowered following surgical or bromocriptine

Received August 26, 1982 treatment. In addition, a decrease in pituitary responsiveness to luteinizing hormone-releasing hormone (LHRH) has been reported in hyperprolactinemic women (Bohnet et al., 1976) and in lactating rats with an elevated serum PRL concentration (Muralidhar et al., 1977). In contrast to those reports, other workers (Faglia et al., 1977; Wiebe et al., 1980) have shown the normal responsiveness of the pituitary gland to exogenous LHRH in women with hyperprolactinemia. In the present study, an attempt was made to determine whether exogenously administered PRL could exhibit a negative effect on the hypothalamo-pituitary response to estrogen feedback and LHRH stimulation. 


\section{Materials and Methods}

\begin{abstract}
Animals
Wistar strain rats were housed in group cages (56 rats/cage) under standard lighting conditions (0700$1900 \mathrm{~h}$ light) and allowed food and water ad libitum. When immature rats were used, they were kept in single cages with their mothers (4-6 pups/dam) until the 21 st postnatal day.
\end{abstract}

\section{Experiment 1}

Adult female rats, weighing 200-250 g, were ovariectomized and used for this study 3-4 weeks later. The ovariectomized animals were primed subcutaneously with a single dose of $20 \mu \mathrm{g}$ estradiol benzoate (EB ; in $0.1 \mathrm{ml}$ sesame oil). This day was designated as day- 0 . On day-3, a second injection of $20 \mu \mathrm{g}$ EB was administered. All injections were given at noon and the concentration of serum gonadotropins was determined at $1800 \mathrm{~h}$ on the day of the second injection.

Subcutaneous injection of rat PRL $(5 \mu \mathrm{g} / 0.2 \mathrm{ml}$ normal saline) was also given daily in the morning $(1100 \mathrm{~h})$ for 3 days beginning on day-1. Purified rat PRL (NIAMDD-rat PRL-B-2, biological potency= 20 i. u./mg by crop sac assay) was provided by Dr. A. F. Parlow through the Hormone Distribution Program, NIAMDD. Controls were treated with an equivalent volume of $0.9 \%$ saline alone.

\section{Experiment 2}

Immature female rats were treated with rat PRL $(5 \mu \mathrm{g} / 0.2 \mathrm{ml}$ normal saline) or vehicle alone daily in the morning $(0800 \mathrm{~h})$ between day 30 and day 32 of life. At $0900 \mathrm{~h}$ on day 32, the animals were injected intraperitoneally with synthetic LHRH (100 ng/100 g BW, Teikoku Hormone Mfg. Co., Ltd., Tokyo, Japan) or an equivalent volume $(0.5 \mathrm{ml})$ of normal saline only. Blood samples were collected $15 \mathrm{~min}$ later and the serum levels of gonadotropins and PRL were estimated.

\section{Hormone Assays}

Blood was drawn from the trunk following decapitation. After centrifugation the serum was separated and kept frozen at $-20^{\circ} \mathrm{C}$. Serum LH, FSH and PRL concentrations were measured by RIA system based on the method of NIAMDD instructions, using NIAMDD-anti-rat LH-Serum-S-4, NIAMDanti-rat FSH Serum-9, and NIAMD-anti-rat PRL Serum-6 as antibodies, respectively. The amounts of the hormones were experessed in terms of NIAMDDrat LH-RP-1 for LH, NIAMD-rat FSH-RP-1 for FSH, and NIAMD-rat PRL-RP-1 for PRL.

Statistical differences between two means were tested by Student's $t$-test.

\section{Results}

Effect of PRL on positive estrogen feedback mechanism

In ovariectomized rats primed with a single injection of $\mathrm{EB}$, a second dose of $\mathrm{EB}$ induced a highly significant $(\mathrm{p}<0.001)$ rise in serum LH levels $6 \mathrm{~h}$ later (Table 1). However, serum FSH levels were not statistically different from those in the controls. No suppression of the $\mathrm{LH}$ release in response to EB administration was observed, even when the second injection of EB was preceded by PRL treatment. There was no statistical difference in the serum $\mathrm{LH}$ concentration, when compared with the values for the control animals treated with normal saline alone. Serum PRL levels in the PRLtreated animals were found to be significantly $(\mathrm{p}<0.001)$ higher than in any other group.

\section{Effect of $P R L$ on pituitary responsiveness to LHRH}

Serum gonadotropin levels measured 15 min after LHRH administration in 32-dayold female rats were significantly higher than

Table 1. Serum LH, FSH and PRL concentrations $6 \mathrm{~h}$ after estradiol benzoate (EB) administration in ovariectomized, EB-primed rats, and the effects of exogenously administered PRL on the feedback action of estrogen.

$\left.\begin{array}{lcccc}\hline \text { Group } & \text { No of Rats } & \text { LH }(\mathrm{ng} / \mathrm{ml}) & \text { FSH }(\mathrm{ng} / \mathrm{ml}) & \text { PRL }(\mathrm{ng} / \mathrm{ml}) \\ \hline \text { Control } & 6 & 48.3 \pm 7.1 \\ \text { EB alone } & 6 & 680.0 \pm 78.1\end{array}\right] * \begin{aligned} & 286.0 \pm 22.5 \\ & \text { EB+saline }\end{aligned}$

Mean \pm SEM, NS ; not significant, $*$; $<0.001$

Controls are ovariectomized, EB-primed animals, 
Table 2. Serum gonadotropin levels $15 \mathrm{~min}$ after the intraperitoneal injection of synthetic LHRH or $0.9 \%$ saline in 30-day-old female rats, and the effects of the pretreatment with PRL on LHRH-promoted gonadotropin release.

\begin{tabular}{|c|c|c|c|c|c|c|c|}
\hline Group & LHRH injection & No of Rats & LH (ng/ml) & & FSH (ng/ml) & & PRL (ng/ml) \\
\hline \multirow{2}{*}{ A } & - & 5 & $56.3 \pm 7.6$ & \multirow[t]{2}{*}{$*$} & $203.3 \pm 11.57$ & \multirow{2}{*}{$* *$} & $83.3 \pm 9.8$ \\
\hline & + & 5 & $426.2 \pm 38.8$ & & $272.0 \pm 20.6$ & & $102.4 \pm 12.3$ \\
\hline \multirow{2}{*}{ B } & - & 6 & $51.5 \pm 6.3$ & \multirow{2}{*}{$*$} & $217.0 \pm 15.27$ & \multirow{2}{*}{$* * *$} & $467.3 \pm 30.6$ \\
\hline & + & 6 & $380.6 \pm 31.6$ & & $296.8 \pm 32.5]$ & & $517.6 \pm 23.3$ \\
\hline
\end{tabular}

Mean \pm SEM, $*$ p $<0.001, * * ; \mathrm{p}<0.02, * * * ; \mathrm{p}<0.05$

Group A; pretreated with saline

Group B; pretreated with PRL

those in saline-injected controls $(\mathrm{LH}, \mathrm{p}<$ 0.001 ; FSH, $\mathrm{p}<0.02)$. High serum concentrations of both $\mathrm{LH}$ and $\mathrm{FSH}$ following LHRH were also observed in the animals pretreated with PRL and were not statistically different from the values for the controls pretreated with vehicle alone (Table 2). In the PRL-primed groups, the statistical difference in serum gonadotropin levels was estimated between the animals injected with LHRH and the controls treated with saline (LH, $\mathrm{p}<0.001 ; \mathrm{FSH}, \mathrm{p}<0.05$ ).

\section{Discussion}

It has been suggested that unphysiologically high levels of circulating PRL appear to affect the various subunits of the reproductive axis in a negative manner. At the pituitary level, PRL seems to act to desensitize the gland to the action of LHRH. Muralidhar et al. (1977) have reported that ovine PRL administered prior to LHRH causes an inhibition of the pituitary response to LHRH stimulation in lactating rats. In an in vitro study, Wuchenich and Cheung (1981) have demonstrated the decreased LH release in response to LHRH when the pituitary gland from ovariectomized rats was incubated with ovine PRL. The results of the present study, however, indicate that an increase in the serum concentrations of PRL has no influence on LHRH-stimulated gonadotropin release. Although not shown, our results with humans also showed that in most patients with hyperprolactinemia the gonadotropin response to LHRH is comparable to that in normal women during the early stage of the menstrual cycle. These findings are in agreement with the earlier reports (Glass et al., 1975; Aono et al., 1979; Van Campenhout, 1980) in which a normal or exaggerated response to LHRH in hyperprolactinemic women is observed, although others were unable to comfirm this (Bohnet et al., 1976). Corbey et al. (1977) have reported that, in general, the hyperprolactinemic women demonstrating a high gonadotropin response to LHRH have higher basal concentrations of serum estrogen than in the low gonadotropin-responding women. Therefore, it seems likely that, as was shown in normally cycling women (Wang et al., 1980), the response of the pituitary to LHRH in hyperprolactinemic patients may depend, in part, on the circulating estrogen levels, not the PRL. On the basis of those findings, the possibility that PRL itself modulates gonadotropin release by direct action on the pituitary gland is rendered less likely.

Excessive PRL might also act at the hypothalamic level to interfere with spontaneous episodic gonadotropin release (Boyar et al., 1974; Bohnet et al., 1976) and inhibit the normal positive feedback effect of estrogen on gonadotropin secretion (Glass et al., 1975; Faglia et al., 1977; Aono et al., 1979). In addition, L'Hermite and coworkers (1978) have reported that hyperprolactinemia induced experimentally by sulpiride administration is associated with an impaired positive 
estrogen feedback mechanism. These findings suggest that the hypothalamus is directly affected by PRL and may be a major site for the reduced reproductive function which accompanies hyperprolactinemic states. However, in our present study, the positive estrogen feedback mechanism remains intact in PRL-primed rats, suggesting that PRL itself cannot affect gonadotropin release by its direct action on the feedback effect of estrogen. One explanation for the discrepancies between the results is that in our study the increased level of serum PRL is induced by exogenous PRL and, therefore, short lived. The effect of longterm administration of PRL on the estrogen feedback remains to be elucidated.

Although the disturbances causing idiopathic hyperprolactinemia are still unclear, the proposed mechanism is felt to be related to a functional derangement of the hypothalamic control of PRL and gonadotropin secretion, including the catecholamine and opioid system as well as the steroid feedback mechanism (Bohnet and Schneider, 1977; Evans et al., 1982). Since we could not demonstrate any effect of exogenous PRL on the hypothalamo-pituitary axis, it is possible that PRL may not act directly on the hypothalamus and pituitary gland to inhibit their responses to the action of gonadal steroids and LHRH, respectively. Travaglini et al. (1979) have shown that the restoration of adequate progesterone levels can normalize the $\mathrm{LH}$ response to estrogen administration in hyperprolactinemic women, suggesting that the reduced reproductive potential accompanying the hyperprolactinemic state may not be due to the direct action of excess PRL on the hypothalamo-pituitary axis but may mediated through altered ovarian steroidogenesis.

\section{Acknowledgements}

The authors wish to thank Dr. A. F. Parlow and the Rat Pituitary Hormone Distribution Program of the NIAMDD for kindly donating of PRL and antisera for RIA, and Miss M. Yoh, Miss T. Inoue and Mrs. M. Sato for their technical assistance.

\section{References}

Aono, T., A. Miyake, T. Yasuda, K. Koike and K. Kurachi (1979). Restoration of oestrogen positive feedback effect on LH release by bromocriptine in hyperprolactinaemic patients with galactorrhoeaamenorrhoea. Acta Endocrinol. (Copenh.) 91, 591600.

Bohnet, H.G., H.G. Dahlén, W. Wuttke and H.P.G Schneider (1976). Hyperprolactinemic anovulatory syndrome. J. Clin. Endocrinol. Metab. 42, 132-143.

Bohnet, H.G. and H.P.G. Schneider (1977). Prolactin as cause of anovulation. In : Prolactin and Human Reproduction (P.G. Crosignani and C. Robyn eds.), Academic Press, New York. pp. 153-159.

Boyar, R.M., S. Kapen, J.W. Finkelstein, M. Perlow, J.F. Sassin, D.K. Fukushima, E.D. Weitzman and L. Hellman (1974). Hypothalamic-pituitary function in diverse hyperprolactinemic states. J. Clin. Invest. 53, 1588-1598.

Corbey, R. S., R. M. Lequin and R. Rolland (1977). Hyperprolactinemia and secondary amenorrhea. In : Prolactin and Human Reproduction (P.G. Crosignani and C. Robyn eds.), Academic Press, New York. pp. 203-215.

Evans, W.S., M.J. Cronin and M.O. Thorner (1982). Hypogonadism in hyperprolactinemia: proposed mechanism. In : Frontiers in Neuroendocrinology, Vol. 7 (W.F. Ganong and L. Martini eds.), Raven Press, New York. pp. 77-122.

Faglia, G., P. Beck-Peccoz, P. Travaglini, B. Ambrosi, M. Rondena, A. Paracchi, A. Spada, G. Weber, R. Bara and A. Bouzin (1977). Functional studies in hyperprolactinemic states. In: Prolactin and Human Reproduction (P. G. Crosignani and C. Robyn eds.), Academic Press, New York. pp. 225238.

Glass, M. R., R. W. Shaw, W. R. Butt, R. Logan Edwards and D.R. London (1975). An abnormality of oestrogen feedback in amenorrhoea-galactorrhoea. Br. Med. J. 111, 274-275.

L'Hermite, M., J. Delogne-Desnoeck, A. MichauxDuchene and C. Robyn (1978). Alteration of feedback mechanism of estrogen on gonadotropin by sulpirideinduced hyperprolactinemia. J. Clin. Endocrinol. Metab. 47, 1132-1136.

Muralidhar, K., R. Maneckjee and N.R. Moudgal (1977). Inhibition of in vivo pituitary release of luteinizing hormone in lactating rats by exogenous prolactin. Endocrinology 100, 1137-1142.

Travaglini, P., R. Elli, B. Ambrosi, M. Ballabio., P. Moriondo and G. Faglia (1979). Serum LH increase after estradiol and progesterone administration in 
hyperprolactinemic women. J. Endocrinol. Invest. 2, 407-411.

Van Campenhout, J. (1980). Pituitary responses to LH-RH in patients with amenorrhea or oligomenorrhea associated with galactorrhea. In : The $\mathrm{LH}$ Releasing Hormone (C. G. Beling and A. C. Wentz eds.), Masson Publishing, New York. pp. 275-283. Wang, C. F., B. L. Lasley and S. S. C. Yen (1980). Pituitary function studies by multiple LH-RH stimulation. In: The LH-Releasing Hormone (C. G. Beling and A.C. Wentz eds.), Masson Publishing,
New York. pp. 157-165.

Weib, R.H., M.R. Soules and C.B. Hammond (1980). LH-RH testing in amenorrhea-hyperprolactinemia. In: The LH-Releasing Hormone (C. G. Beling and A.C. Wentz eds.), Masson Publishing, New York. pp. 285-293.

Wuchenich, N.E. and C.Y. Cheung (1981). Prolactin suppression of pituitary responsiveness to LHRH in rat anterior pituitaries in vitro. Fed. Proc. 40, 388. 